\title{
ANALYSIS OF SERIES VARIATIONAL CHARACTERISTICS AND CAUSES OF TARIM RIVER BASIN RUNOFF UNDER THE CHANGING ENVIRONMENT
}

\author{
ZHANG, X. Y. ${ }^{1^{*}}-\mathrm{ZUO}, \mathrm{Q} . \mathrm{T}^{2}$ \\ ${ }^{1}$ North China University of Water Resources and Electric Power, Zhengzhou 450011, China \\ ${ }^{2}$ College of Water Conservancy and Environment, Zhengzhou University \\ Zhengzhou 450001, China \\ *Corresponding author \\ e-mail: zhangxiuyu@ncwu.edu.cn \\ (Received $28^{\text {th }}$ Oct 2016; accepted $28^{\text {th }}$ Feb 2017)
}

\begin{abstract}
Tarim River, whose mainstream water relies mainly on supplies from origin area rivers, is a typical inland river in the arid area of our country. Based on measured hydrological data and methods of linear tendency estimate and Mann-Kendall non-parametric test, this article taking '4 origins and 1 mainstream' of Tarim River Basin as the research object, makes a research on the characteristics and laws of historical hydrological processes together with the spatial and temporal characteristics of regional climate change, and analyzes the impact of climate change on water cycle and runoff changes. The research results indicate that temperature and precipitation in Tarim River Basin present an increasing trend. Among the four original rivers of the Tarim River, the annual runoff of Aksu River, Kaikong River, and Yarkant River all shows a significantly increasing trend, the first two of which enjoys an obvious increase, while the annual runoff of Hotan River demonstrates a slight increase. Influenced by human activities, the annual runoff of the Tarim River mainstream has tended to decrease for many years. With the special geographical location and basin structure, the Tarim River Basin is mainly supplied by meltwater of glacier and snow. Although the rising precipitation and the increasing melt glacier keep the ample runoff in the origin area in the near future, the water resource in the area will be confronted with severe problems in the long run.
\end{abstract}

Keywords: runoff changes; trend test; mutation diagnosis; mutability analysis; changing environment

\section{Introduction}

Water is the source of life, the basic element of production and the base of ecology. Problems like flood, lack of water, dirty water and muddy water have become the main restraining factors of the world's economic and social development. China, as the biggest developing countries, suffers from the shortage of water resources, the average water resources per person being only a quarter that of the worldwide level, and its uneven distribution in time and space. With the fast development of economy and society and the deterioration of water environment, the problem of water shortage in China, especially in the northwest and north China inland is very serious (Qian and Zhang, 2001).

Climate change, a global issue of common concern to the international community today, has become one of the major global environmental problems, and will have a great impact on the global ecological environment, water resources, social and economic areas or departments. The effects of climate change on water resources at present concentrate 
mainly on the influence of climate change on water. Owing to the complexity of the problem, the impact of climate change on river ecology, water quality and extreme hydrological events have relatively fewer quantitative study (Zhang and Wang, 2007; Zhang et al., 2009). The profound change of the atmospheric system will inevitably affect the global water cycle process, the changes of the hydrological factors such as precipitation, evaporation, and then greatly enhance the occurrence frequency of the extreme hydrologic event, change the river basin and regional water balance, thus affecting river basin and regional distribution of water resources. Obviously, considering China's large population base and congenital water resource conditions not being favourable, coupled with the effects of future climate change, the contradiction between supply and demand of water resources will inevitably become acuter.

Trim River is the longest continental river in China, the rare rainfall in the basin, intense evaporation and dry climate making water resources relatively poor and the ecological environment being fragile. Since the 1950s, because of the influence of human activities and climate change, and disorderly development and inefficient use of water resources, multiple source rivers have broken away from the main stream one after another, therefore, the water yield from the source rivers into the main stream out of the river source water has been falling.

The building of Daxihaizi reservoir in 1972 basically stopped the water from Tarim River upstream, downstream river channel fully cut off, degree of mineralization of ground water increasing, Tema Lake dried up, populus diversifolia on both sides of the main river dying largely. The downstream green corridor which is of strategic significance, therefore, is on the brink of destruction, the deteriorated ecological environment has become a main factor for the sustainable development of society and economy.

Water yield of Tarim River springs mainly from the supplies of Akesu River, Hetian River, Yarkant River and Kaidou River - Kongque River (hereinafter referred to as a Kaikong River) in the origin area of the Tianshan mountains and the Kunlun mountains, around which are rich glaciers and permanent snow. Mountain glaciers and the mountainous precipitation form the water system of Tarim River Basin, and mountain temperature and precipitation determines the water yield of runoffs and mainstreams of the Tarim River origin (Zuo et al., 2004; Chen and Xu, 2005; Jiang and Xia, 2007; Jiang et al., 2007; Chen et al., 2008; Ma, 2008; Tao et al., 2009; Lv and Zhang, 2010; Zhang et al., 2010; Chen et al., 2011; Zuo, 2011; Zuo and Zhang, 2015).

Therefore, this article, through analyzing the secular changing characteristics of controlling hydrologic runoff and regional climate change in terms of" 4 origins and 1 mainstream"of Tarim River, mainly studies the influence of environment on temporal and spatial changes of runoffs and explores the influence of environmental changes on mechanism of water cycle and changing process of the runoffs. 


\section{Research data and the method}

\section{Profile of the research area}

Trim River is the longest continental river in China, located in the south of Xinxiang Uyghur autonomous region and the whole basin is made up of the nine river systems around Tarim Basin which consist of 144 rivers such as Akesu River, Kashgar River, Yarkant River, Hetian River, Kongque River, Dina River, Weigan River, Kuche River, Keliya River and Qarqan River. Geographically, with the total area of about $1.02 \times 106 \mathrm{~km} 2$, the whole river basin includes the nine water systems around the Tarim Basin and its main streams, the Taklimakan Desert and eastern desert region,. From the origin of the Yarkant River, Trim River is about 2, $350 \mathrm{~km}$ long, with the 1, $321 \mathrm{~km}$-long main stream.

With the aggravating human activities in the middle and upper reaches of Ta River, especially the development of oasis agriculture, the Tarim River basin has undergone huge evolution, various water systems breaking away from their main streams (Fu et al., 2008; Xu and Zuo, 2011).

At present, the only three water systems has the natural hydraulic relation, especially surface water, with the main streams of Tarim River: Akesu River, Yarkant River, Hetian River, known as the upstream three origins. Couple with Kaikong River which supplies Tarim River with water through Kuta canal, they are known as the four origins, as shown in Figure 1.

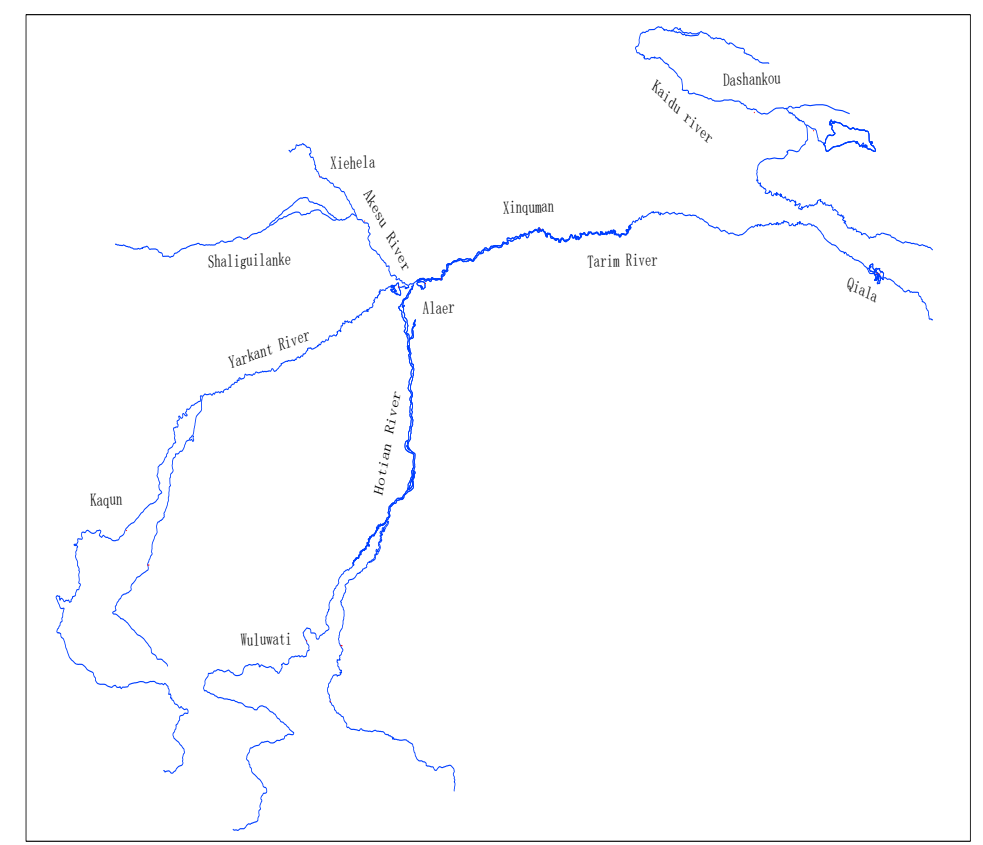

Figure 1. The distribution sketch map of the " 4 origins and 1 mainstream" water system of Tarim River Basin 


\section{Data}

This study selected the representative hydrological stations along the " 4 origins and 1 mainstream" of Tarim River river, known as Akesu River, Hetian River, Kaidu River and Ta River.

As for Aksu River, the selected hydrological stations are Shaliguilanke on the Tuoshigan River, Xiehela on Kumalake River. besides, other hydrological stations includes Kaqu on Yarkant River, Wuluwati on Hetian River, Alaer, Xinquman and Kala on the main stream of Ta River ( see Figure 1).

Hydrological data comes from surface water resource database of Xinxiang Hydrology and Water Resources Survey, origin stations using the observation data from 1961 to 2010, main stream hydrological station using the observation data from 1961 to 2008. At the same time,

Four typical weather stations are selected from the research area, and the meteorological data originates from observation data from 1961 to 2010, which are provided by the nationwide meteorological stations of the National Meteorological Administration.

\section{Research method}

\section{Trend analysis}

Whether the evolution law of hydrologic meteorological elements has a significant trend can be obtained through the time series analysis of various elements. The tendency can reflect the general law of changes of different elements. There are many ways to the current trend analysis. In the study of hydrology and weather, moving average, linear tendency estimate, double smoothing, triple smoothing, accumulative anomaly Kendall test method and so on. Linear tendency estimation is mainly adopted to analyze the tendency of temperature, rainfall and runoff in this paper.

\section{Mutability analysis}

The changes of hydrologic meteorological elements display not only an overall trend but also dramatic variation characteristics. Mutability analysis is the way to estimate the time, frequency and range of the dramatic variation elements. At present, the common methods of mutability analysis are slide $t$ detected method, Pettitt method, Lepage method and Mann-Kendall method etc. Among them, Mann-Kendall methods is a nonparametric test method, and this method is first put forward by foreign scholars, and is used for sequence smoothness of nonparametric test. After further perfection and improvement, the current algorithm is formed. The Mann-Kendall method can objectively measure the sequence mutation point, and has a better reaction to the change trend of the sequence in different stages. The Mann - Kendall method is mainly adopted, and sliding $\mathrm{t}$ test is used to check in this paper.

The counting process of Man-Kendall mutation test is as follows. For the time series X with N samples: 
(1) Construct an order list.

$$
S_{k}=\sum_{i=1}^{k} r_{i} \quad(k=2,3, \cdots, n)
$$

Where, if $x_{i}>x_{j}$, then $r_{i}=1$. if $x_{i} \leq x_{j}$, then $r_{i}=0 \quad(j=1,2, \cdots, i)$.

(2) Give a definition to the statistics, when the time series is assumed to be a random independence series.

$$
U F_{k}=\frac{\left[S_{k}-E\left(S_{k}\right)\right]}{\left[\operatorname{var}\left(S_{k}\right)\right]^{1 / 2}} \quad(k=1,2, \cdots, n)
$$

Where, $U F_{1}=0 . E\left(S_{k}\right), \operatorname{var}\left(S_{k}\right)$ is the mean value and variance of accumulative number, calculated through formulas 3 and formulas 4 if $x_{1}, x_{2}, \cdots, x_{n}$ is mutual independence and have the same continuous distribution.

$$
\begin{gathered}
E\left(S_{k}\right)=\frac{n(n+1)}{4} \\
\operatorname{var}\left(S_{k}\right)=\frac{n(n-1)(2 n+5)}{72}
\end{gathered}
$$

(3) Trend significance test

Statistics $\mathrm{UF}_{\mathrm{i}}$ conforms to the standard normal distribution. It is calculated according to the time sequence order statistic sequence $\mathrm{X}$ as $\mathrm{x}_{1}, \mathrm{x}_{2}, \ldots \mathrm{x}_{\mathrm{n}}$, given significance level $\alpha$, according to the normal distribution table. If $\left|U F_{i}\right|>U_{\alpha}$, there is significant trend indicates sequence.

(4) Mutation site test

Plotting statistic $U F_{i}$ and reverse sequence calculation of statistic calculation $U B_{i}$ (value multiplied by -1) respectively, it obtains curves $c_{1}$ and $c_{2}$. If the intersection 
point of curves $c_{1}$ and $c_{2}$ is within a certain confidence interval, then it argues that the time of intersection may be the beginning of mutation.

Considering the influence of the time series autocorrelation in the study, it tests the autocorrelation coefficient of delay 1 before the trend test. If the autocorrelation coefficient is significant, it proceeds to white noise. The specific calculation steps are as follows.

(5) Calculate the nonparametric slope $\beta$.

$$
\beta=\operatorname{median}\left[\left(x_{j}-x_{i}\right) /(j-i)\right] \quad(i<j)
$$

(6) Eliminate the trend term of the series, get a new time series Y.

$$
y_{t}=x_{t}-\beta * t
$$

(7) Calculate the coefficient of autocorrelation of series Y, when the lag time is 1.

The confidence level is $5 \%$. If the coefficient is not significant, use the original $\mathrm{X}$ for trend test. On the contrary, to eliminate the noise, then get series $Y^{\prime}$.

$$
y_{t}^{\prime}=y_{t}-r_{1} * y_{t-1}
$$

(8) Add the trend term to series $Y^{\prime}$, get series $Y^{\prime \prime}$ for trend test.

$$
y_{t}^{\prime \prime}=y_{t}^{\prime}-\beta * t
$$

\section{Results and analysis}

\section{Analysis of regional climate change characteristics}

In order to study the characteristics of regional climate change, Aheqi station and Wushi station are chosen to stand for the meteorological stations at the origin zone of Tarim River, Shaya station stand for the meteorological stations at upper reaches and Yuli station stand for the meteorological stations at middle reaches, the temperature and rainfall sequence data of these meteorological stations are made a trend analysis of.

National assessment report on climate change points out that over the past century the degree of the surface temperature changes is higher than the national average value and precipitation also has an increasing trend (Ding, 2007) in the northwest region. Figure 2 shows clearly that in recent 50 years, annual average temperature of the Tarim River 
basin has displayed a rising trend, and the temperature rise is the main characteristic of climate change in the Tarim River basin, especially since the mid-1980s. At the same time, annual precipitation of the Tarim River basin in the recent 50 years also has showed a rising trend, especially since the mid-1980s. So the increasing precipitation is also an important feature of climate change in the Tarim River basin, and the degree of precipitation increase in the origin area is higher than that in the plain and basin. Studying the trend of precipitation in origin area showed an obvious increase trend in 1990. Before1990, the period of precipitation increase and decrease trend basically appeared alternately, and they were roughly equal; Precipitation showed a trend of growth from 1990 to 2010, and the increase degree reached a "significant" level.

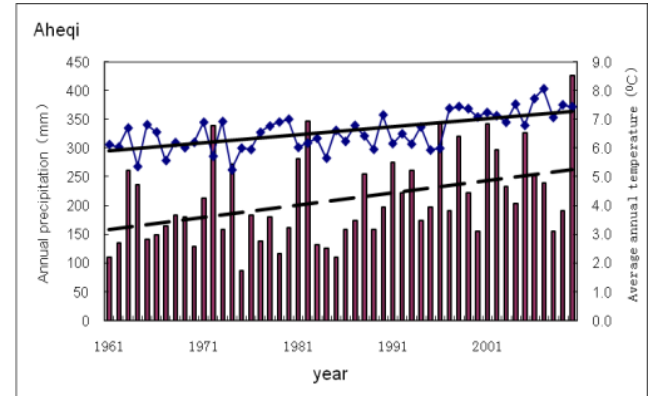

(a)

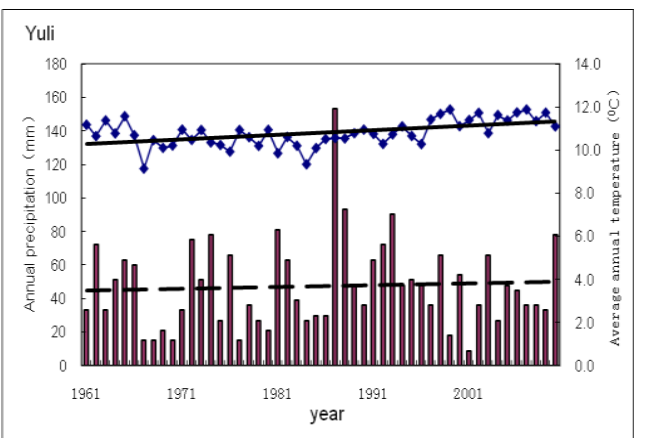

(c)

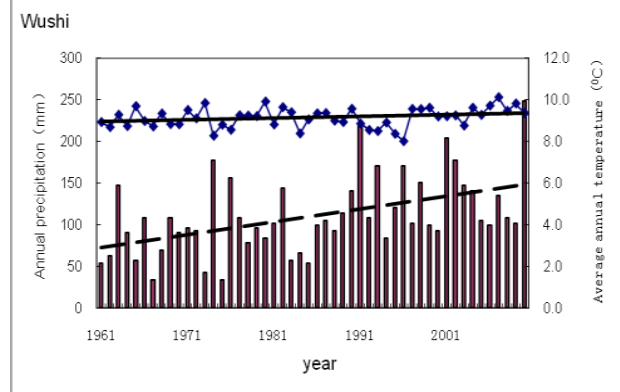

(b)

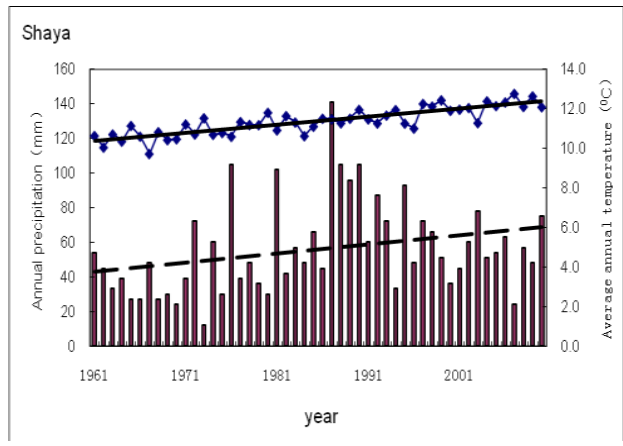

(d)

Figure 2. Change tendency of annual temperature and precipitation from various weather stations in Tarim River Basin

\section{Variation characteristics and genetic analysis of runoff sequence}

The four origins of hydrological stations are river output mountain control station. Rivers in the origin area are mainly supplied by glaciers and permanent snow, so runoff change is mainly affected by climate change and human activities have little influence on it. The Aral hydrological stations, the Xinquman hydrological station and Qiala hydrological station in the main Tarim River are located in the desert oasis areas of the river basin, which are strongly influenced by human activities. 
From the calculation of the runoff deviation coefficient of the output mountain station over the years, it shows that the $\mathrm{C}_{\mathrm{v}}$ value is between $0.15 \sim 0.25$, and the smaller value reflects the characteristics of the origin area: the stable output mountain runoff and smaller annual variation range. The $\mathrm{C}_{\mathrm{v}}$ of Alpha station in the main stream is 0.27 , the Xinquman station is 0.29 , and Qiala station is 0.80 . The dispersion coefficient $C_{v}$ value of hydrologic station is bigger, which shows that annual variation range of the Tahe river is larger. Characteristic values of the hydrological station and water basin are shown in Table 1.

Table 1. Hydrological stations characteristic values in the '4 origins and 1 mainstream' of Tarim River Basin

\begin{tabular}{|c|c|c|c|c|c|c|}
\hline \multirow{2}{*}{\multicolumn{2}{|c|}{ Name of rivers }} & \multirow{3}{*}{$\begin{array}{c}\begin{array}{c}\text { Hydrological } \\
\text { station }\end{array} \\
\text { Shaliguilanke }\end{array}$} & \multirow{3}{*}{$\begin{array}{l}\text { The catchment } \\
\text { area }\left(\mathrm{km}^{2}\right) \\
19166(10206)\end{array}$} & \multicolumn{2}{|c|}{ mean annual runoff } & \multirow{3}{*}{$\begin{array}{c}\text { Time order } \\
\text { (a) } \\
50\end{array}$} \\
\hline & & & & \multirow{2}{*}{$\frac{\mathrm{C}_{\mathrm{V}}}{0.24}$} & \multirow{2}{*}{$\frac{\left(10^{8} \mathrm{~m}^{3}\right)}{28.66}$} & \\
\hline \multirow{2}{*}{ Akesu River } & Toxkan River & & & & & \\
\hline & Kumarik River & Xiehela & 12816（2306） & 0.22 & 48.58 & 50 \\
\hline Yarkant River & Yarkant river & Kaqun & 50248（47378） & 0.19 & 65.99 & 50 \\
\hline Hotian River & Kara kashgar river & Wuluwati & 19983 & 0.25 & 20.73 & 50 \\
\hline Kaikong River & Kaidu river & Dashankou & 19022 & 0.17 & 35.15 & 50 \\
\hline Tarim River & Main stream & Alaer & & 0.27 & 43.38 & 48 \\
\hline Tarim River & Main stream & Xinquman & & 0.29 & 35.43 & 48 \\
\hline Tarim River & Main stream & Qiala & & 0.80 & 5.49 & 48 \\
\hline
\end{tabular}

Note: The numbers in the brackets are catchment area in China.

\section{The diagnosis of runoff mutations}

Runoff mutation is an important and widespread phenomenon. The Mann-Kendall method which is objective and accurate for runoff mutation test is chosen to analyze the every control station's annual runoff mutation point of Tahe "4 origins and 1 mainstream", and sliding t method is used to contrast and check the analysis of the result. The sliding t test is simple and can determine mutation visually, and Mann-Kendall can not only make the mutation clear but also avoid the use of sliding $t$ test which is more difficult to deal with the situation of the mutation appearance in the years of sequence's start and end.

Based on the method of Mann-Kendall, the mutation test results of annual runoff in eight hydrologic stations of "4 origins and 1 mainstream"of Tarim River Basin are analyzed and shown in Fig. 3. The analysis results indicate that: 1) The year of 1993 witnessed a runoff mutation in Shaligulake hydrological station of Tuoshigan River, and the annual runoff had an upward trend. Its yearly runoff exceeded the critical value in 2002 and had an obvious increasing trend; 2) The year of 1988 witnessed a runoff mutation in Xiehela hydrological station of Kumalake River, and the annual runoff had an upward trend. Its yearly runoff exceeded the critical value in 2002 and had an obvious 
increasing trend; in 1998; 3) The year of 1995 witnessed a runoff mutation in Kaqun hydrological station of Yarkand, and the annual runoff had an upward trend; 4) There was a less runoff change in Hotan hydrological station of Wuluwati River and annual runoff had a slight upward trend; 5) The year of 1996 witnessed a runoff mutation in Dashankou hydrological station of Kaikong River, and the annual runoff had an upward trend . Its yearly runoff exceeded the critical value in 2002 and had an obvious increasing trend; 6) The year of 1968 witnessed a runoff mutation in Alaer hydrological station of Tarim River mainstream, and the annual runoff had an obvious downward trend. It also had a mutation change in 2004 and the annual runoff began to rise, but annual runoff had another downward trend in 2007; 7) The year of 1970 witnessed a runoff mutation in Xinqunman hydrological station of Tarim River mainstream. The annual runoff has an obvious downward trend. Its yearly runoff exceeded the critical value in 1992 and had an obvious decreasing trend;. Since 2000, water resources in all Tarim River mainstream had been brought under unified management, the annual runoff had an upward trend, but it began to reduce after 2007; 8) The year of 1974 witnessed a runoff mutation in Qiala hydrological station of Tarim River mainstream. The annual runoff has an obvious downward trend. Its yearly runoff exceeded the critical value in 1976 and had an obvious decreasing trend. Since 2000, water resources in all Tarim River have been brought under unified management, and the annual runoff has an upward trend.

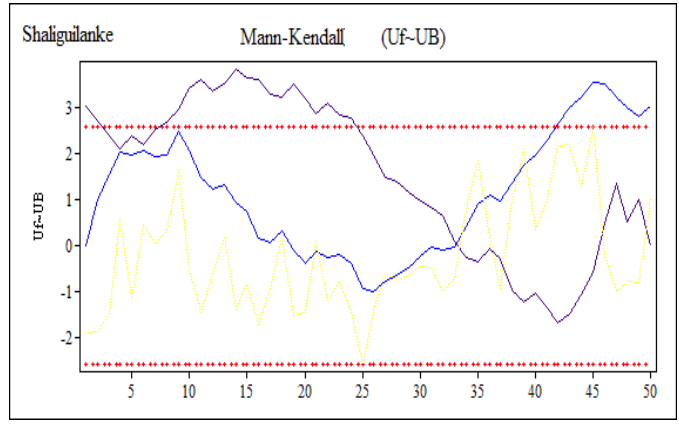

(a)

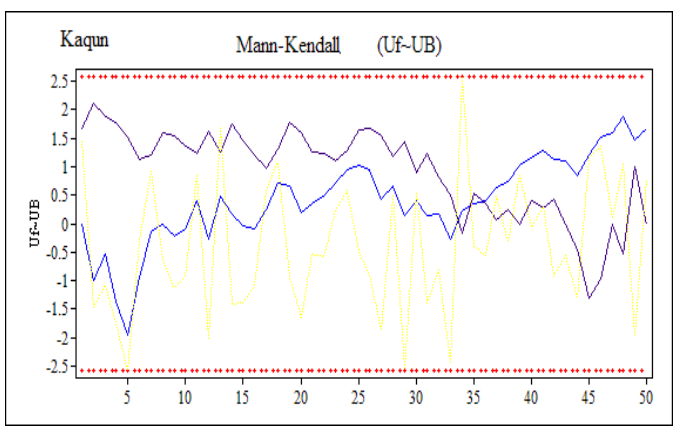

(c)

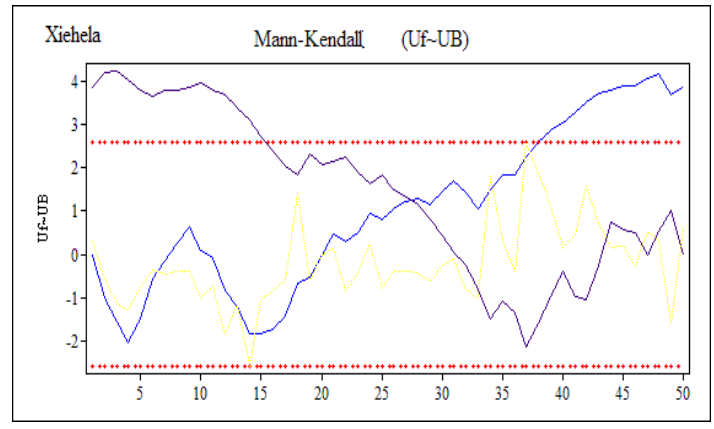

(b)

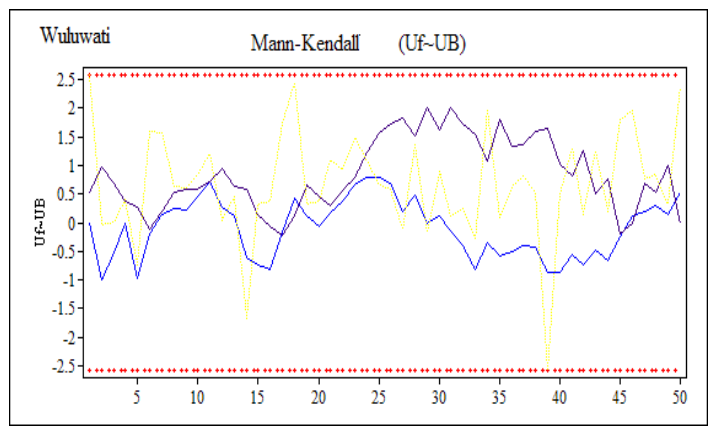

(d) 


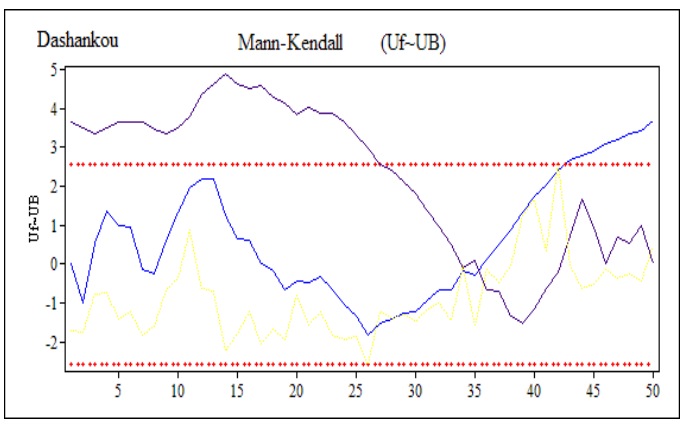

(e)

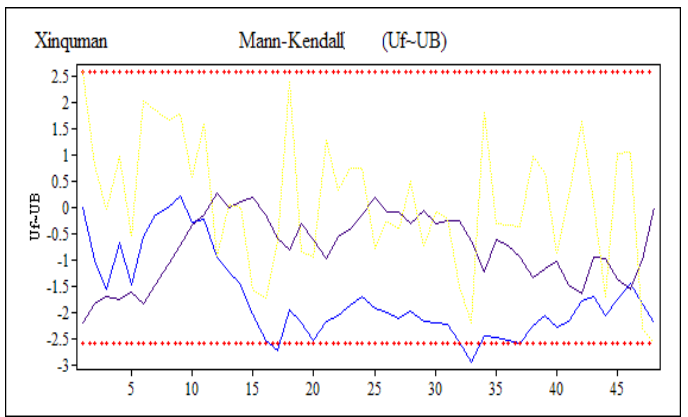

( g)

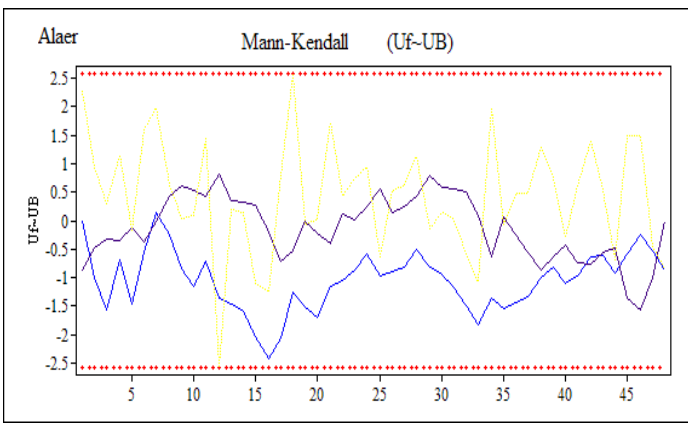

(f)

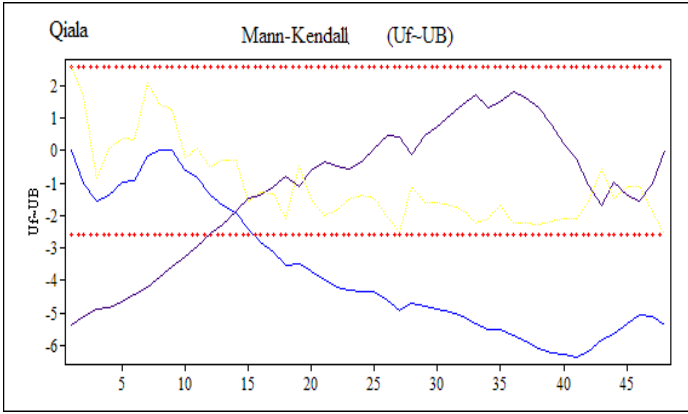

$(\mathrm{h})$

Figure 3. Test results of runoff mutation site of hydrological stations by using the methods of Mann-Kendall test in the '4 origins and 1 mainstream' of Tarim River Basin

\section{Runoff Trends and Cause Analysis}

Climate change and human activities inevitably affect the elements of the water cycle, and the most direct change on water resources is the change of surface runoff. Based on linear tendency estimate method, an analysis on the runoff changing process and long-term trend is made of the main control hydrological stations of " 4 origins and 1 mainstream" of Tarim River Basin (as shown in Fig.4). The research results indicate that among the four original rivers of the Tarim River, the annual runoff of Aksu River, Kaikong River, and Yarkant River all shows a significantly increasing trend, the first two of which have an obvious increase, while the annual runoff of Hotan River demonstrates a slight increase. The Tarim River mainstream has an obviously decrease tend.

As shown in Figure 4, both Xiehela station of the Aksu River and Dashankouzhan station of the Kaikong River have the obvious growth in the annual runoff with the growth coefficient of 0,2636 and 0.2123 respectively. Kaqun station of the Yarkand River and Shaliguilanke station of the the Aksu River show an evident growth in the annual runoff with the growth coefficient of 0.163 and 0.1565 respectively. Wuluwati station of Khotan River shows a slight growth trend and the growth coefficient is 0.0176. Aral, Xiquman and QIala stations of the main river course of the Tarim show an obvious decrease trend in the annual runoff with the decrease coefficient of $-0.0903,-0.2663$ and -0.1823 respectively. 


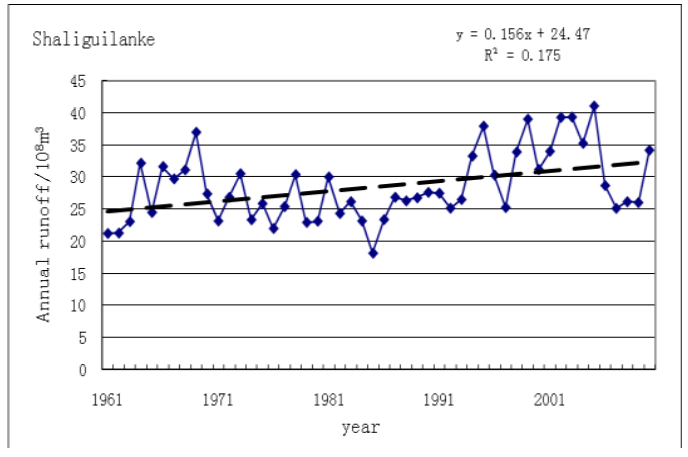

(a)

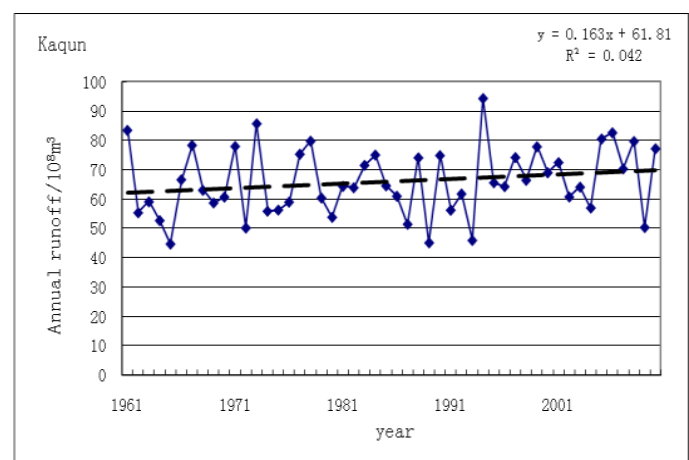

(c)

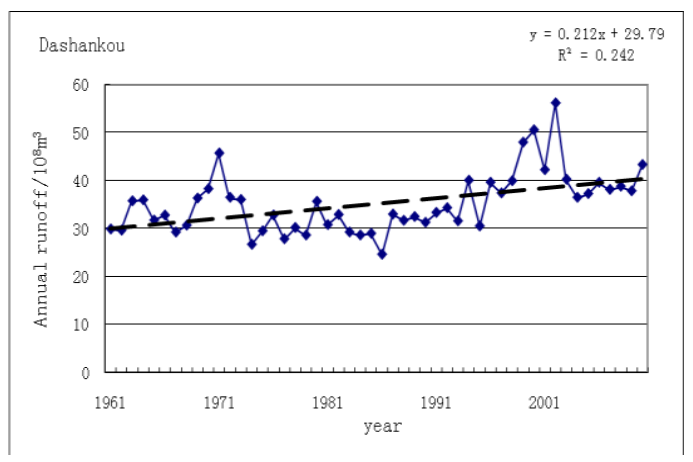

(e)

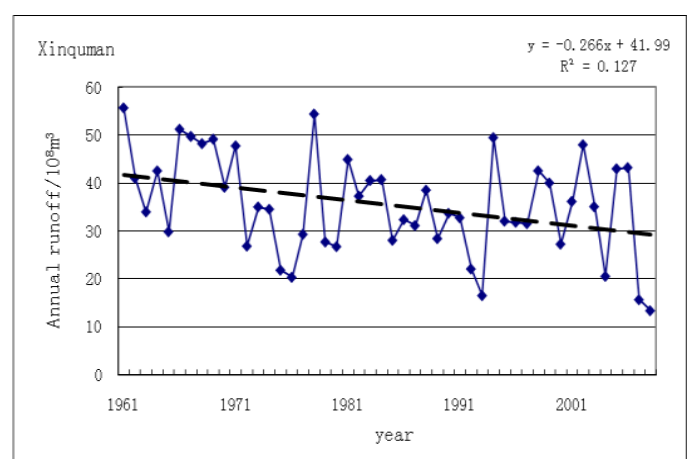

(g)

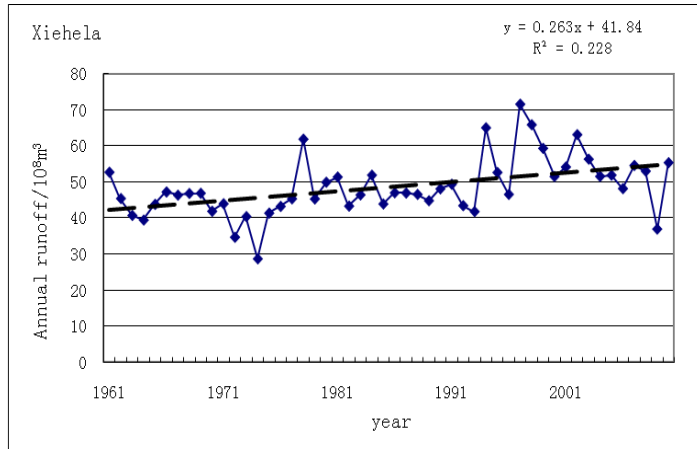

(b)

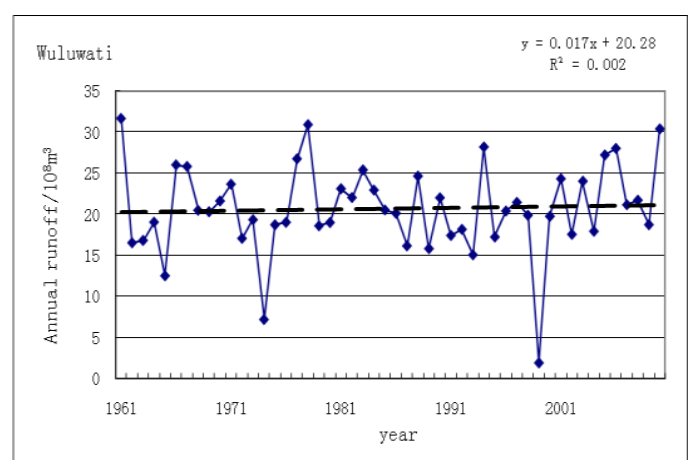

(d)

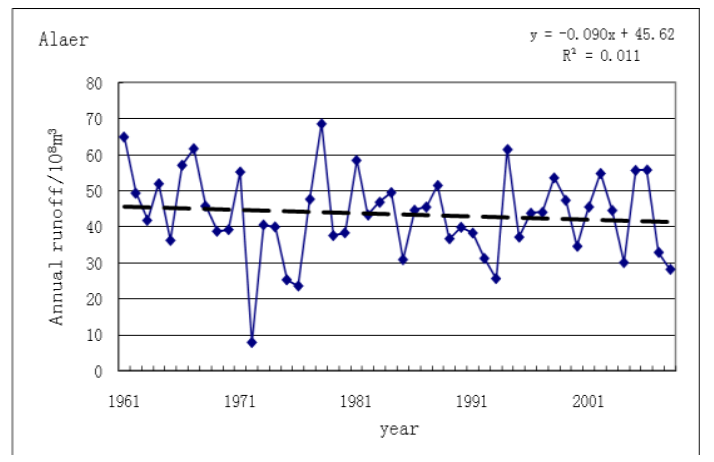

(f)

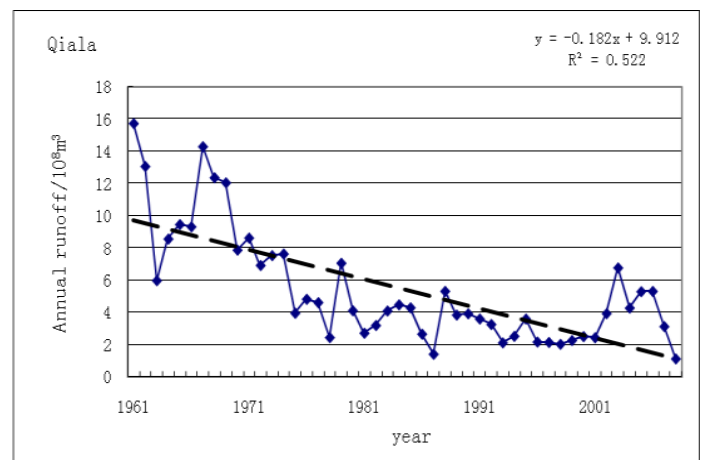

(h)

Figure 4. Change tendency of the annual runoff of control hydrological stations in the " 4 origins and 1 mainstream" of Tarim River Basin 
Surface runoff of Origin area increases while stream flow of mainstream region shows declining trend. It shows that the runoff increase of mountain pass in the origin area doesn't cause the improvement of the Tahe River runoff. The main reason of the runoff decrease year by year in the main stream of Tahe River is the huge influence of human activity. According to statistics, a large-scale development of soil and water has began in the Tarim River region since the 1950s. Economic and social rapid development in various regions and the continuous increase of irrigated areas caused the increasing demand of production and life water. Annual runoff change trend in the three control stream hydrological stations in Tarim River indicates that in the approaching downstream there is a more significantly decreasing trend, which is also the reason of main stream gradually drying up. Studies have pointed out that due to the influence of human activity, annual runoff of Tarim River presents a decreasing trend for many years, and the worst is in the late 1990s. After implementation of ecological water transfer in Tahe River basin since 2000, annual runoff in downstream has begun to getting better, which corresponds with the results in this paper.

\section{Conclusion}

According to the analysis of the climate change characteristics (the temperature and precipitation) and the change of annual runoff river at control hydrological stations, conclusions can be obtained:

(1) The increase of temperature and precipitation has become the main characteristics of climate change in the Tarim River Basin, and degree of increasing precipitation in origin area has reached a significance level. Climate change affects the water cycle process of the Tarim River source area. Because temperature rise has increased melting glaciers and origin area rainfall increases significantly, the runoff at the mountain pass increases obviously. The results show that the mountain pass runoff in the origin area has an obvious increase and it is also more sensitive to climate change. With the continuous rise of temperature and melting glaciers and the change of precipitation, the surface runoff of origin area will also increase. Studies have pointed out that if the temperature rise $1{ }^{\circ} \mathrm{C}$, the Tianshan No. 1 glacier equilibrium line will go up $81 \mathrm{~m}$, and the glacier equilibrium line will go down $31 \mathrm{~m}$ when precipitation rises 20\% (Liu et al., 1998). No. 1 glacier is a small glacier in north slope of Tianshan mountain area which is less than 2 $\mathrm{km}^{2}$, and the area of mountain glacier inTarim River Basin is about $23220 \mathrm{~km}^{2}$ (including foreign area). Plenty of glacier areas will reduce due to global warming. Although in the near future it will bring a lot of glacier melt water, the the critical point of glacier runoff by changing from more to less may also appear. As the global climate warming, it may lose the glacier "solid water tower" as arid zone, which is irreplaceable. Therefore, as to the water resources situation of the Tarim River Basin, it is relatively optimistic in the short term while it will face more serious problems in the long run.

(2) The surface runoff is increasing in the origin area of Tarim River basin and the runoff of the main stream area is declining, which shows that the increase of the runoff at the mountain pass of the origin area does not cause the improvement of the Tarim River 
runoff. The great impact of human activities on the origin area is the main reason that the runoff of Tarim River is decreasing year by year. The disorderly development and inefficient use of water and soil resources make the living and production water demand increase. The newly increasing water at the mountain pass has been the developed and utilized in the origin area, which doesn't better the water situation. The change trend of the three control hydrologic stations in the upper, middle and lower reaches of Tarim River main stream suggests that in the approaching downstream there is a more significantly decreasing trend about river runoff. The reasons of the decrease trend of the runoff along the stations greatly include the influence of human activity and the increase of water evaporation caused by the rising temperatures, etc. But it should be mainly due to the influence of the human activities. For more than half a century, the agricultural production scale of the oasis has expanded unceasingly in the river area of the main stream and the population of the oasis and the water consumption have continuously increased, thus causing the above phenomenon consequentially. The impact of the population increase and the development of the social economic in Tarim River basin on the water resource are greater than that of climate factors. Human activities are important reason for affecting the safety of the ecological environment in the downstream of the Tarim River Basin.

The analysis of climate change characteristics in the Tarim River Basin and the variation characteristics on "four headstreams and one main streams" controlling hydrologic runoff in this paper reveals the environment changes have an impact on the spatial and temporal variation of the runoff. The situation of the water resources in Tarim River basin are badly affected under the dual effects of climate change and human activities. The problem on the deterioration of the ecological environment caused by the water shortage of Tarim River is the result of the natural environment evolution and human activities, but human activities are the mainly factor. Therefore, to implement the most strict water resources management system in Tarim River basin in the future is the inevitable choice to correspond with the climate change, improve the integrated water resources management and adaptation ability, realize the harmony of the human and water in whole river basin, the ecological security and the sustainable development of social economy. The conclusion not only has an important reference value for the theory research on the change environment of the water cycle in the inland river basin, but also has an important strategic significance for the sustainable economic development and social progress of Chinese western region.

Acknowledgments. This study was supported by the University Key Scientific Research Projects of Henan Province (15A570004), the University Young Backbone Teacher Training Program of Henan Province (2016GGJS-075), and the High Level Talents Scientific Research Project of NCWU. 


\section{REFERENCES}

[1] Chen,Y.N., Pang,Z.H., Hao, X.M. (2008): The Periodic changes of stream flow in the last 40 years in Tarim River Basin, Xinjiang, China. -Journal of Hydrological the Processes 22:4214-4221

[2] Chen,Y.N., Xu,Z.X.(2005): Plausible impact of globe climate change on water resources in the Tarim River Basin, China. -Science in China: the Series D, 13 (1): 65-73.

[3] Chen,Z.S., Chen,Y.N., Xu,C.C.(2011): Nearly 50 a to Tarim river annual runoff change trend and prediction. -Journal of geography in arid areas 1: 43-51.

[4] Ding,Y.H.(2007): National assessment report on climate change. Beijing: science press, 265-269.

[5] Fu,L.X., Chen,Y.N., Li,W.G.(2008): Three streams of the Tarim river area, the impact of climate change on runoff. -Journal of geography in arid areas 31 (2): 237-242.

[6] Jiang,Y., Xia,J.(2007): In the summer of Tarim river basin runoff variation characteristics and its response to climate change. -Journal of resources science 29 (3): 45-52.

[7] Jiang,Y., Zhou,C.H., Cheng,W.M.(2007): Streamflow trends and hydrological response to climatic change in Tarimheadwater basin. -Journal of Geographical Sciences 1: 51-61.

[8] Liu,S.Y., Ding,Y.J., Wang,N.L.(1998): Tianshan Urumqi river head no. 1 glacier mass balance sensitivity to climate change research. -Journal of glacial permafrost 20 (1): 9-13.

[9] Lv,J.Q., Zhang,X.W.(2010): HeTian river annual runoff sequence variation characteristics and driving factors analysis. -Journal of hydroelectric power 29 (5): 165-169.

[10] Ma,Y.M.(2008): Under the influence of climate is given priority to with snowmelt water supply's runoff change.-Journal of desert and oasis meteorology 2(1): 33-34.

[11] Qian,Z.Y., Zhang,G.D.(2001): China water resources sustainable development strategy research. -Beijing: China water conservancy and hydropower press.

[12] Tao,H., Mao,H.Y., Bai,Y.G.(2009): 45 years in the Tarim river basin, the impact of climate change on runoff research.-Journal of plateau climate 28 (4): 854-860.

[13] Xu,Y.F., Zuo,Q.T.(2011): The Tarim river basin climate change and the runoff variation characteristics analysis. -Water and electricity energy science 29 (12): 1-4.

[14] Zhang,J.B., Wu,G.H., Wang,Q.M.(2010):. The Restoring environ - getting flows and improving riparian ecosystem of Tarim River.-Journal of Arid Land 2 (1): 43-50.

[15] Zhang,J.Y., Wang,G.Q.(2007): Climate change impact on hydrology and water resources research.-Beijing: science and technology press.

[16] Zhang,J.Y., Wang,G.Q., Liu,J.F.(2009): The domestic and foreign research progress of the effects of climate change on water.-Journal of Yangtze river 40 (8): 39-41.

[17] Zuo,Q.T.(2011): The calculation of water resource utilization and threshold. -Journal of water conservancy 11: 1372-1378.

[18] Zuo,Q.T., Li,J., Ma,J.X.(2004): Effluents to Tarim river water conveyance risk analysis method. -Journal of arid area in geography 27 (3): 361-366.

[19] Zuo,Q.T., Zhang,X.Y.(2015): Dynamic carrying capacity of water resources under climate change. -Journal of water conservancy 46 (4): 387-395. 